\title{
Article \\ Recovery of Tantalum and Manganese from Epoxy-Coated Solid Electrolyte Tantalum Capacitors through Selective Leaching and Chlorination Processes
}

\author{
Wei-Sheng Chen (1), Chih-Yuan Hsiao * and Cheng-Han Lee *(1)
}

check for

updates

Citation: Chen, W.-S.; Hsiao, C.-Y.;

Lee, C.-H. Recovery of Tantalum and Manganese from Epoxy-Coated Solid Electrolyte Tantalum Capacitors through Selective Leaching and Chlorination Processes. Materials 2022, 15, 656. https://doi.org/ $10.3390 / \mathrm{ma} 15020656$

Academic Editors: Adam Cwudziński and Lifeng Zhang

Received: 28 December 2021

Accepted: 14 January 2022

Published: 16 January 2022

Publisher's Note: MDPI stays neutral with regard to jurisdictional claims in published maps and institutional affiliations.

Copyright: (c) 2022 by the authors. Licensee MDPI, Basel, Switzerland. This article is an open access article distributed under the terms and conditions of the Creative Commons Attribution (CC BY) license (https:// creativecommons.org/licenses/by/ $4.0 /)$.
Department of Resources Engineering, National Cheng Kung University, No. 1 Daxue Road, Tainan 701401, Taiwan; kenchen@mail.ncku.edu.tw

* Correspondence: n46091091@gs.ncku.edu.tw (C.-Y.H.); n48091013@gs.ncku.edu.tw (C.-H.L.)

\begin{abstract}
Electronic products are ever growing in popularity, and tantalum capacitors are heavily used in small electronic products. Spent epoxy-coated solid electrolyte tantalum capacitors, containing about 22 wt.\% of tantalum and 8 wt.\% of manganese, were treated with selective leaching by hydrochloric acid and chlorination after removing the epoxy resin, and the products converted, respectively, to $\mathrm{Mn}(\mathrm{OH})_{2}$ and $\mathrm{TaCl}_{5}$. The effects of acid type, acid concentration, liquid-solid ratio, and reaction time were investigated to dissolve the manganese. The optimal selective leaching conditions were determined as $3 \mathrm{~mol} / \mathrm{L}$ of $\mathrm{HCl}, 40 \mathrm{~mL} / \mathrm{g}$ at $25^{\circ} \mathrm{C}$ for $32 \mathrm{~min}$. Next, residues of selective leaching after washing and drying were heated with ferrous chloride to convert to pure $\mathrm{TaCl}_{5}$. Mixing $48 \mathrm{wt} . \%$ of chloride and $52 \mathrm{wt} . \%$ of residues for a total of $5 \mathrm{~g}$ was conducted to complete the chlorination process in the tube furnace at $450{ }^{\circ} \mathrm{C}$ for $3 \mathrm{~h}$. A total of $2.35 \mathrm{~g}$ of Ta was collected and the recovery of Ta achieved $94 \%$. Finally, $\mathrm{Mn}(\mathrm{OH})_{2}$ and $\mathrm{TaCl}_{5}$ were separated and purified as the products.
\end{abstract}

Keywords: tantalum capacitor; manganese; selective leaching; chlorination; recovery

\section{Introduction}

The demand for tantalum capacitors is steadily increasing due to the popularity of small electronic products. At the same time, small electronic products are eliminated rapidly, which represents a large amount of waste [1-3]. Tantalum is a transition element with an atomic number of 73, an atomic weight of 180.95 , and a melting point of about $3000{ }^{\circ} \mathrm{C}\left(2980 \pm 20^{\circ} \mathrm{C}\right)$, which is slightly lower than tungsten and rhenium. The resources of tantalum, which usually co-exist with niobium, are mainly from the coltan or columbite $[4,5]$, making refinement difficult due to their similar chemical characteristics. Tantalum was discovered in 1802, one year after niobium, and the average amount of tantalum in the Earth's crust is 2 ppm [6]. Therefore, it is feasible to recover tantalum from tantalum capacitors that do not contain niobium [7-9]. Tantalum has high capacitance/unit volume, high thermal stability, and high oxidation resistance which can be used in electronic and biotechnology industries [10-12]. In the year 2016, about 34\% of tantalum was used in manufacturing capacitors, followed by superalloy, chemical, sputtering target, mill product, and carbide industries [11,13].

Epoxy-coated solid electrolyte tantalum capacitors (EcSETCs) consist of electrodes, an epoxy resin, and wires. Electrodes include cathodes, anodes, and dielectrics. Anodes and dielectrics are made of tantalum and a small amount of its oxide powder, while cathodes are made of manganese oxide, graphite, and silver paste. The epoxy resin, which has silicon added to enhance its thermal durability, comprises halogenated compounds.

Tantalum-rich electrodes are sealed with epoxy resin. Hence, the removal of epoxy resin is conducted before any recovery process. Many methods can remove the epoxy resin, such as combustion [14], pyrolysis [15-18], solubilization $[19,20]$, and supercritical water 
treatment [21]. After removing the epoxy resin, the recovery of tantalum mainly chooses one of two methods: the hydrometallurgy process and the chlorination process. In the hydrometallurgy process, leaching agents such sulfuric acid $\left(\mathrm{H}_{2} \mathrm{SO}_{4}\right)[22,23]$, hydrofluoric acid (HF) [24], or a mixture of both [14,15], all applied at normal temperatures, have been investigated. Previous studies have indicated that pressure leaching using HF has better leaching efficiency [7]. After leaching, several extractants such as MIBK [25], CHO [26], and Alamine $336[17,27]$ have been studied. The drawbacks of traditional extraction are high volatility and low thermal stability. To overcome these shortcomings, ionic liquids are studied in hydrometallurgy [24,28,29]. In the chlorination process, chlorine gas or hydrogen applied to tantalum and niobium raw ore [6] or ferrous chloride applied to tantalum capacitors [15,30-32] have both been studied.

In most of the studies mentioned above, the recovery of tantalum is higher in the hydrometallurgy process but the purify of tantalum is higher in the chlorination process. In this study, a feasible recycling process that combines the advantage of hydrometallurgy and chloride metallurgy was designed. After first removing the epoxy resin from EcSETCs, selective leaching was conducted to remove the manganese and increase the recovery of tantalum. Previous studies on leaching manganese from the different wastes were researched [33-38] to investigate the best leaching efficiency and increase the recovery rate of manganese. Low concentrate ordinary inorganic acid, which is applied to dissolve the manganese through selective leaching, was chosen instead of hydrofluoric acid, which is more dangerous and a pollutant. The parameters were investigated, such as acid concentrate, liquid-solid ratio, and reaction time to increase the leaching efficiency of manganese. Then, manganese hydroxide was obtained through chemical precipitation. Furthermore, chlorination with ferrous chloride was used in the recovery of tantalum. The manganese hydroxide and the tantalum chloride were separated individually as the final productions in this study.

\section{Materials and Methods}

\subsection{Materials}

The EcSETCs in this study were made in Taiwan with $100 \mu \mathrm{F} / 16$ Volt. An EcSETC include an epoxy resin, wires, and an electrode. The mass ratio of each physical component is shown in Table 1. The elements in EcSETCs were dissolved with $90 \% v / v$ of aqua regia and $10 \% v / v$ of hydrofluoric acid and the ion concentration in the solution measured by inductively coupled plasma optical emission spectrometry (ICP-OES; VISTA-MPX, Varian, Palo Alto, CA, USA). The concentration of the main element compositions is shown in Table 2. The sulfuric acid ( $\geq 98.0 \%)$, nitric acid $(\geq 65.0 \%)$, hydrofluoric acid $(\geq 45 \%)$, hydrochloric acid $(\geq 37.0 \%)$, and ferrous chloride $(\geq 99 \%)$ were purchased from Uni-Onward Corp (New Taipei City, Taiwan). Chemicals used in this study were all of the analytical quality. The purity of the nitrogen gas used in pyrolysis was $99.0 \%$ from Yunshan Gas Co., Ltd. (Tainan, Taiwan).

Table 1. The mass ratio of each physical component in the EcSETCs (wt.\%).

\begin{tabular}{ccc}
\hline Electrode & Epoxy Resin & Wire \\
\hline $25.67 \%$ & $53.41 \%$ & $17.92 \%$ \\
\hline
\end{tabular}

Table 2. The concentration of the main element compositions in the EcSETCs (wt.\%).

\begin{tabular}{ccccccc}
\hline Element & Ta & Mn & Ni & Fe & Si & Ag \\
\hline wt. $\%$ & $20-22 \%$ & $8 \%$ & $10 \%$ & $8 \%$ & $4-6 \%$ & $1 \%$ \\
\hline
\end{tabular}




\subsection{Experimental Procedures}

\subsubsection{Pretreatment}

Silicon added in the epoxy resin is the main factor affecting tantalum recycling because it is recovered with tantalum through chlorination. On the other hand, iron and nickel from wires also affect the efficiency of selective leaching. Due to the reasons mentioned above, pretreatment is necessary. The epoxy resin can be removed through pyrolysis with nitrogen gas. Thermogravimetric analysis (TGA, Perkin Elmer, Pyris Diamond TG/DTA, Waltham, MA, USA) was used to determine the pyrolysis temperature in the pretreatment. After the pyrolysis process, grinding and washing with deionized water to flush the epoxy resin was conducted. Next, the electrode was crushed to increase the specific surface area that can improve the efficiency of selective leaching. Finally, the iron and nickel were removed from the wires through magnetic separation. The results of samples without epoxy resin and wires after pretreatment were analyzed by the multi-function environmental field emission scanning electron microscope (EFE-SEM; SU-5000, HITACHI, Chiyoda ku, Japan) with electronic data systems (EDS; EDAX, Mahwah, NJ, USA) and ICP-OES.

\subsubsection{Selective Leaching}

After the pretreatment, the samples were dissolved by the three kinds of inorganic acids. Hydrochloric acid, nitric acid, and sulfuric acid were chosen. The leaching agent with the best efficiency of selective leaching was chosen. Next, parameters such as acid concentration, liquid-solid ratio (L/S ratio), and reaction time were studied. The effect of acid concentration from $0.25 \mathrm{M}(\mathrm{mol} / \mathrm{L})$ to $5 \mathrm{M}(\mathrm{mol} / \mathrm{L}), \mathrm{L} / \mathrm{S}$ ratio from $10 \mathrm{~mL} / \mathrm{g}$ to $50 \mathrm{~mL} / \mathrm{g}$, and reaction time from $2 \mathrm{~min}$ to $256 \mathrm{~min}$ were set to increase the efficiency of selective leaching in this study. After the best parameters were tested and chosen, precipitating manganese hydroxide through adjusting the $\mathrm{pH}$ value was conducted. Next, manganese hydroxide was obtained through calcination as one of the final productions in this study.

\subsubsection{Chlorination}

The residues from the selective leaching process were washed and dried. Subsequently, the samples were heated in the tube furnace with ferrous chloride. After the stoichiometry, $48 \mathrm{wt} . \%$ of residues of selective leaching and $52 \mathrm{wt} . \%$ of ferrous chloride were chosen. Tantalum was collected in the form of $\mathrm{TaCl}_{5}$. The experiment process is shown in Figure 1.

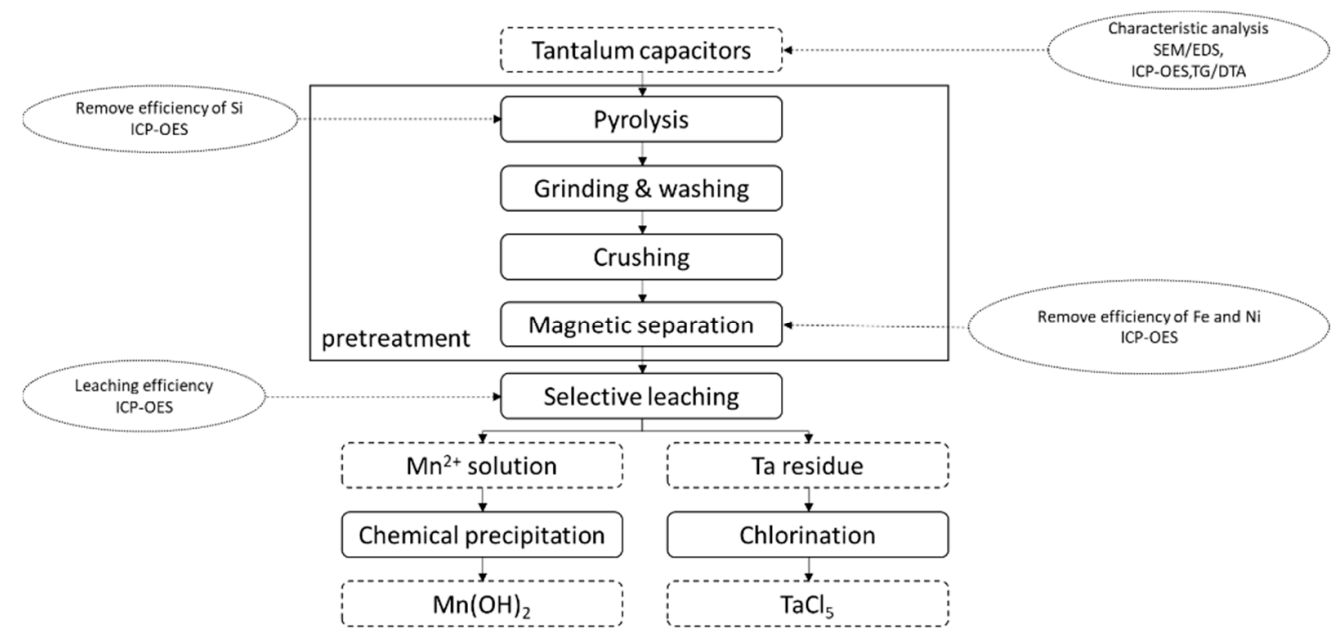

Figure 1. The recovery process of tantalum from EcSETCs. SEM/EDS: multi-function environmental field emission scanning electron microscope with electronic data systems. ICP-OES: inductively coupled plasma optical emission spectrometry. TG/DTA: Thermogravimetric analysis. 


\section{Results and Discussions}

\subsection{Pretreatment}

The epoxy resin and wires are the main factors to affect the recovery efficiency. Therefore, removing the epoxy resin and wires is the first step before any recovery process. A pretreatment process was conducted in this experiment.

Figure 2 illustrates the TG/DTG patterns showing that the first decomposition stage began at $350{ }^{\circ} \mathrm{C}$ until $420^{\circ} \mathrm{C}$. Then, the second stage of decomposition is from $420{ }^{\circ} \mathrm{C}$ to $600{ }^{\circ} \mathrm{C}$. Due to the two stages of decomposition, we speculate that the epoxy resin has two mainly organic phases. According to the TG/DTA patterns, $600{ }^{\circ} \mathrm{C}$ was chosen, and the holding time found through experiments was $10 \mathrm{~min}$ to avoid burning the electrodes. After the pyrolysis process, grinding and washing were conducted to remove the epoxy resin. The SEM-EDS patterns are shown in Figure 3, which demonstrates that silicon was removed from the samples. Next, the wires with iron and nickel were removed through a magnetic separation after crushing. Table 3 shows the removed efficiency of silicon, iron, and nickel in the samples after pretreatment. These data showed that silicon, iron, and nickel were successfully removed through pretreatment.

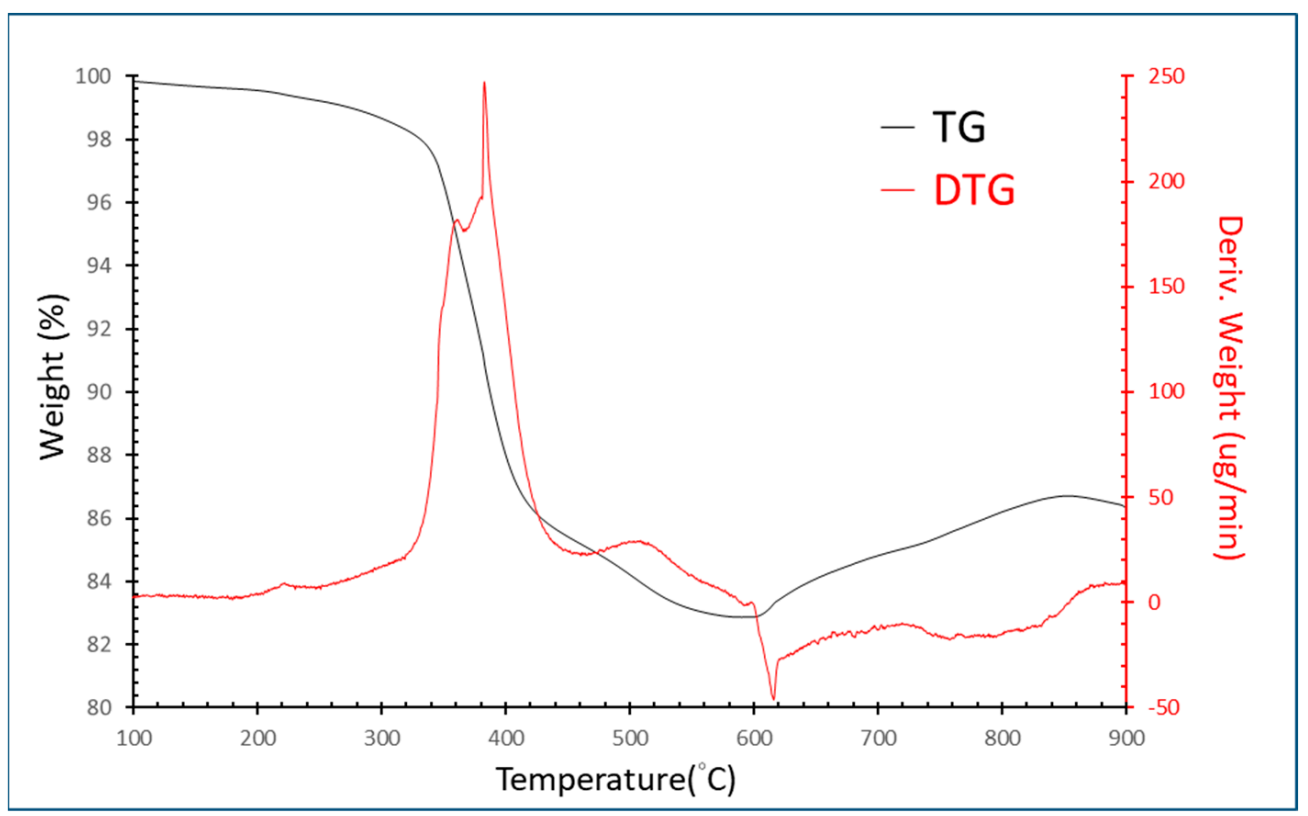

Figure 2. TG/DTG curves of EcSETCs with nitrogen gas $\left(\mathrm{N}_{2}\right)$.

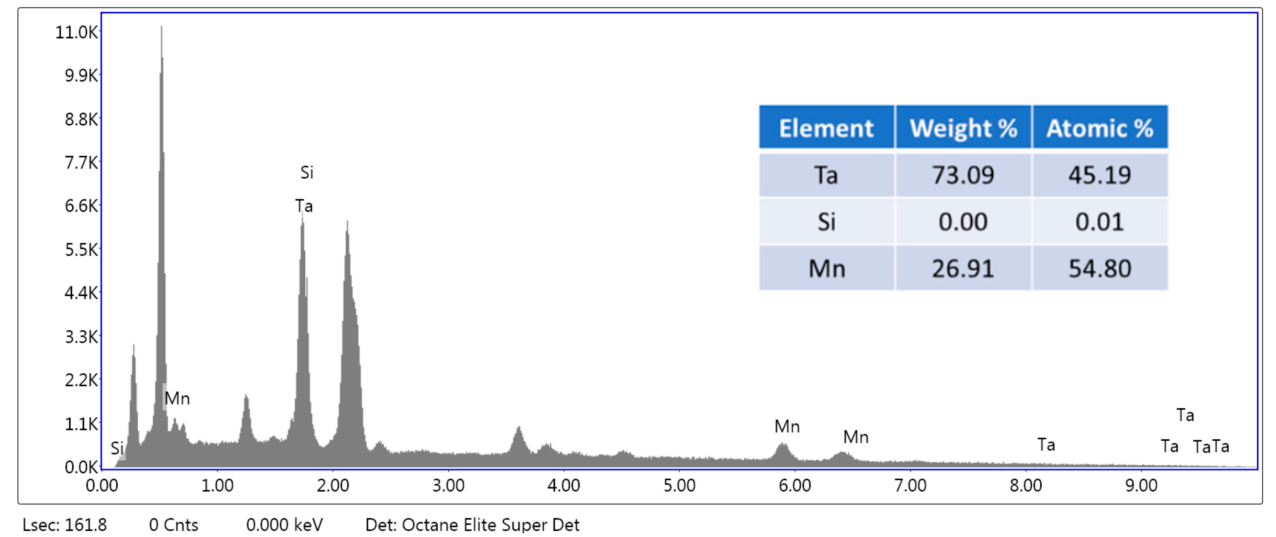

Figure 3. The SEM-EDS patterns of the samples after pyrolysis, grinding, washing, and crushing and the quantitative analysis of samples by SEM-EDS. 
Table 3. Removed efficiency of silicon, iron, and nickel after the pretreatment.

\begin{tabular}{ccccc}
\hline & Si & Fe & Ni & Ta \\
\hline Before & $46.35 \mathrm{mg} / \mathrm{g}$ & $80.30 \mathrm{mg} / \mathrm{g}$ & $90.75 \mathrm{mg} / \mathrm{g}$ & $208.60 \mathrm{mg} / \mathrm{g}$ \\
After & $0.01 \mathrm{mg} / \mathrm{g}$ & $0.40 \mathrm{mg} / \mathrm{g}$ & $0.50 \mathrm{mg} / \mathrm{g}$ & $208.60 \mathrm{mg} / \mathrm{g}$ \\
Removed efficiency & $99.8 \%$ & $99.5 \%$ & $99.4 \%$ & $0 \%$ \\
\hline
\end{tabular}

\subsection{Selective Leaching for Manganese Separation}

After pretreatment, three kinds of inorganic acids were chosen to discuss manganese leaching efficiency. As tantalum does not dissolve in the typical inorganic acids, Table 4 shows that the leaching efficiencies of tantalum are quite low in three kinds of inorganic acids. On the other hand, Table 4 shows that hydrochloric acid had the best leaching efficiency of manganese. Therefore, this study chose hydrochloric acid as a leaching agent to selective leach from the samples after pretreatment.

Table 4. The leaching efficiency of manganese and tantalum with three kinds of inorganic acids.

\begin{tabular}{ccc}
\hline Acid Type & Leaching Efficiency of Mn & Leaching Efficiency of Ta \\
\hline $\mathrm{HCl}$ & $99.7 \%$ & $0.10 \%$ \\
$\mathrm{HNO}_{3}$ & $91.4 \%$ & $0.13 \%$ \\
$\mathrm{H}_{2} \mathrm{SO}_{4}$ & $83.1 \%$ & $0.01 \%$ \\
\hline (Concentration: $5 \mathrm{~mol} / \mathrm{L} ; \mathrm{L} / \mathrm{S}$ ratio: $50 \mathrm{~mL} / \mathrm{g}$; reaction time: $3 \mathrm{~h}$; reaction temperature: $25^{\circ} \mathrm{C}$ ).
\end{tabular}

\subsubsection{Effect of the Hydrochloric Acid Concentration}

The effect of $\mathrm{HCl}$ concentration on the selective leaching of tantalum and manganese was investigated from $0.5 \mathrm{M}$ to $5 \mathrm{M}$ at $25^{\circ} \mathrm{C}$ for $3 \mathrm{~h}$. The results are shown in Figure 4 . The leaching efficiency of manganese increased as the hydrochloric acid concentration increased from $0.5 \mathrm{M}$ to $3 \mathrm{M}$. The fact that tantalum did not dissolve through this step was confirmed. The highest leaching efficiency of manganese was achieved when hydrochloric acid concentration reached $3 \mathrm{M}$. On the other hand, the minimal amount of silver in the cathodes was not dissolved due to the chloride ion from the hydrochloric acid. Here, $3 \mathrm{M}$ of hydrochloric acid was chosen as the optimal concentration in this study.

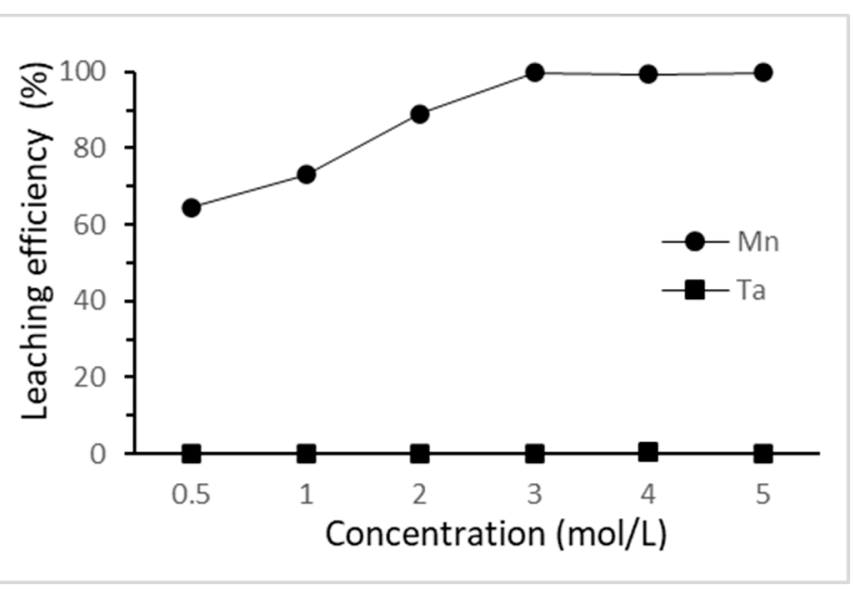

Figure 4. Effect of $\mathrm{HCl}$ concentration on the selective leaching efficiency. (L/S ratio: $50 \mathrm{~mL} / \mathrm{g}$; reaction time: $3 \mathrm{~h}$; reaction temperature: $25^{\circ} \mathrm{C}$ ).

\subsubsection{Effect of the Liquid-Solid Ratio}

The effect of the liquid-solid ratio on the selective leaching of tantalum and manganese was studied from $10 \mathrm{~mL} / \mathrm{g}$ to $50 \mathrm{~mL} / \mathrm{g}$. The results are shown in Figure 5. The leaching efficiency of manganese increased as the liquid-solid ratio increased until the liquid-solid ratio was $40 \mathrm{~mL} / \mathrm{g}$, achieving the best leaching efficiency. Hence, $40 \mathrm{~mL} / \mathrm{g}$ of liquid-solid ratio was chosen as the optimal ratio in this study. 


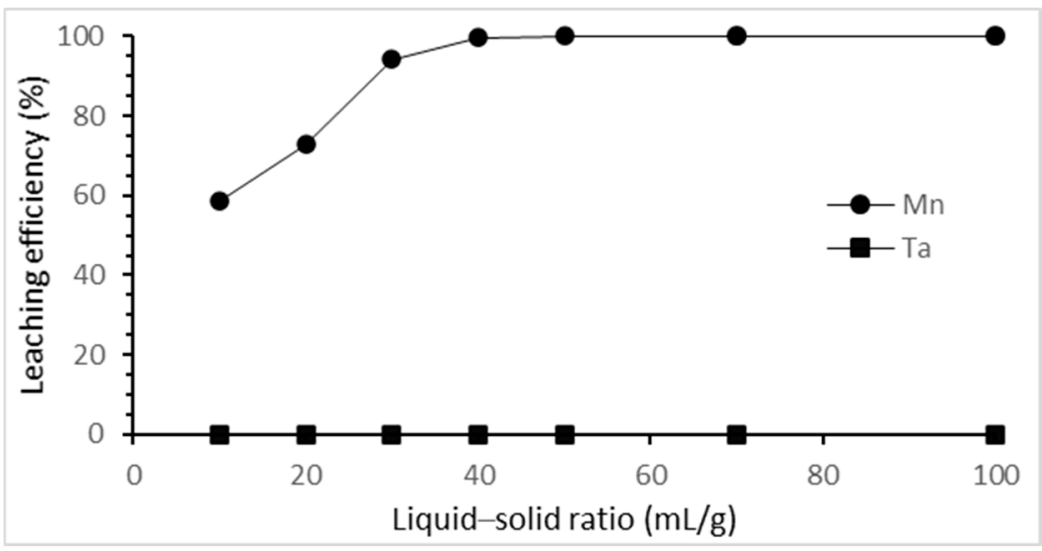

Figure 5. Effect of liquid-solid ratio on the selective leaching efficiency. ( $\mathrm{HCl}$ concentration: $3 \mathrm{M}$; reaction time: $3 \mathrm{~h}$; reaction temperature: $25^{\circ} \mathrm{C}$ ).

\subsubsection{Effect of the Reaction Time}

The effect of the reaction time on the selective leaching of tantalum and manganese was studied from 2 min to $256 \mathrm{~min}$. The results are shown in Figure 6. The leaching efficiency of manganese continues to increase over time until the maximum efficiency is reached in $32 \mathrm{~min}$. At the same time, we wanted to ensure that the tantalum did not dissolve. Therefore, $32 \mathrm{~min}$ was chosen as the optimal time in this study.

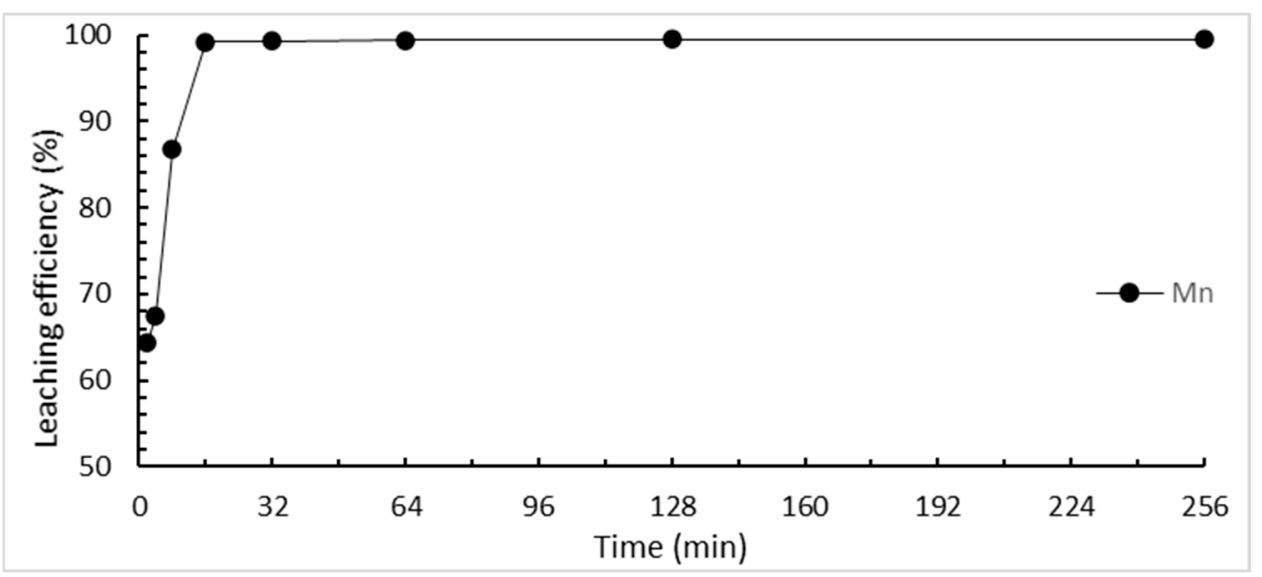

Figure 6. Effect of reaction time on the selective leaching efficiency. ( $\mathrm{HCl}$ concentration: $3 \mathrm{M}$; L/S ratio: $40 \mathrm{~mL} / \mathrm{g}$; reaction temperature: $25^{\circ} \mathrm{C}$ ).

\subsubsection{Manganese Chemical Precipitation}

The precipitation of manganese was investigated using the liquors obtained at the best optimal conditions in this study. Sodium hydroxide $(\mathrm{NaOH})$ was used to adjust the $\mathrm{pH}$ value. The changes in the manganese precipitation as a function of $\mathrm{pH}$ value are shown in Figure 7. The manganese ions begin to precipitate when the $\mathrm{pH}$ value rises. At $\mathrm{pH}=12$, manganese ions almost convert to $\mathrm{Mn}(\mathrm{OH})_{2}$. Hence, $\mathrm{pH}=12$ was chosen as the best parameter for precipitation. After precipitation, $\mathrm{Mn}(\mathrm{OH})_{2}$ was analyzed by the ICP-OES (Varian, Palo Alto, CA, USA) to confirm the compositions. Table 5 shows that the purity of $\mathrm{Mn}$ achieves $98.5 \%$. Due to the addition of $\mathrm{NaOH}$ to adjust the $\mathrm{pH}$ value, the productions contain a small amount of Na. Compared to previous studies [33-38], the results in this study achieved a higher leaching rate and shorter reaction times but used more acid dosage. Thus, the addition of oxidants to decrease the acid dosage and studying the temperature parameter will be discussed in future work. 


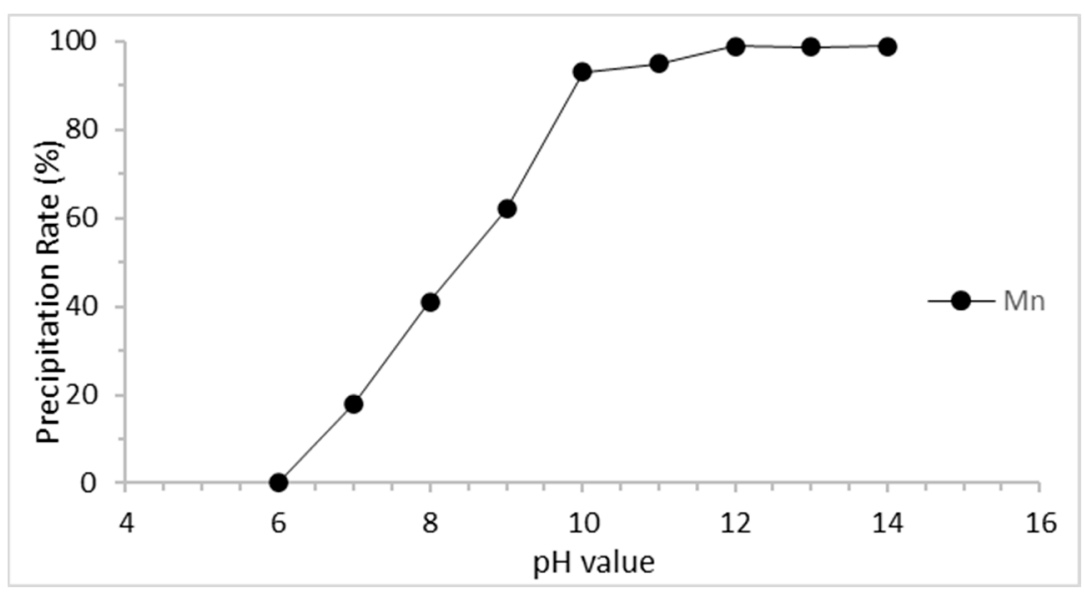

Figure 7. Precipitation rate of manganese.

Table 5. The metals compounds of $\mathrm{Mn}(\mathrm{OH})_{2}$ after precipitation.

\begin{tabular}{cccccc}
\hline Element & $\mathbf{M n}$ & $\mathbf{N a}$ & $\mathbf{F e}$ & $\mathbf{N i}$ & $\mathrm{Ta}$ \\
\hline Content & $98.5 \%$ & $0.7 \%$ & $0.4 \%$ & $0.3 \%$ & $0.1 \%$ \\
\hline
\end{tabular}

\subsection{Chlorination of Tantalum}

After pretreatment and selective leaching, the epoxy resin, wires, and manganese cathodes were removed. Then, chlorination was used to extract the selective leaching residues. After the selective leaching, the remaining residues contain tantalum, graphite, and a small amount of silver chloride $(\mathrm{AgCl})$. According to the previous study, tantalum could selectively react with ferrous chloride $\left(\mathrm{FeCl}_{2}\right)$, and the reaction equation between tantalum and $\mathrm{FeCl}_{2}$ is as follows [31]:

$$
2 \mathrm{Ta}(\mathrm{s})+5 \mathrm{FeCl}_{2}(\mathrm{~g}) \rightarrow 2 \mathrm{TaCl}_{5}(\mathrm{~g})+5 \mathrm{Fe}\left(\mathrm{T}>380{ }^{\circ} \mathrm{C}\right),
$$

The boiling temperature of $\mathrm{TaCl}_{5}$ and $\mathrm{AgCl}$ at standard atmospheric pressure is $234{ }^{\circ} \mathrm{C}$ and $1547{ }^{\circ} \mathrm{C}$, respectively. When the tube furnace reaches the reaction temperature, the generated $\mathrm{TaCl}_{5}$ evaporates into the gas phase while the remaining compounds do not. Next, the gas of $\mathrm{TaCl}_{5}$ enters the condensing equipment to condense into the solid. In this study, the mixture of Ta residues and $\mathrm{FeCl}_{2}$ were heated at $450{ }^{\circ} \mathrm{C}$ for $3 \mathrm{~h}$. The products were dissolved with hydrofluoric acid and analyzed by ICP-OES and the results are shown in Table 6. The recovery of tantalum reaches $94 \%$ and the purity of $\mathrm{TaCl}_{5}$ is about $99 \%$. Comparing to previous studies [15,17,30-32], the results in this study achieved equivalent recovery of Ta in the chlorination process but lower than the hydrometallurgy. Therefore, the detailed reaction mechanism and optimal chlorination process will be discussed in future work.

Table 6. The metals compounds of $\mathrm{TaCl}_{5}$.

\begin{tabular}{ccccc}
\hline Element & Ta & Mn & Fe & Ni \\
\hline Content & $99 \%$ & $0.2 \%$ & $0.5 \%$ & $0.3 \%$ \\
\hline
\end{tabular}

\section{Conclusions}

As the demand for tantalum continuously increases, natural resources are mined and decrease gradually. Finding alternatives to mitigate this situation has become critical. The EcSETCs used in this study contain over $20 \mathrm{wt} . \%$ of tantalum and $8 \%$ of manganese, which have a great potential to provide a tremendous second resource. In this study, the epoxy resins must be removed from the EcSETCs by pyrolysis at $600{ }^{\circ} \mathrm{C}$ for $10 \mathrm{~min}$, grinding, and washing. Next, the separation of iron and nickel through a magnetic separation is 
conducted to affect the efficiency of selective leaching. In summary, $3 \mathrm{M}$ of hydrochloric acid and the liquid-solid ratio of $40 \mathrm{~mL} / \mathrm{g}$ at $25^{\circ} \mathrm{C}$ for $32 \mathrm{~min}$ are chosen as the optimal parameters for selective leaching. With the optimal conditions, the leaching efficiency of Mn can achieve $99 \%$. As Ta does not dissolve in hydrochloric acid, the leaching efficiency of Ta is almost $0 \%$. It means that selective leaching is successful and feasible. After the filtering process, the leaching solution is divided into clear $\mathrm{Mn}$ ion-rich solution and $\mathrm{Ta}$ residues. By adjusting the $\mathrm{pH}$ value to $12, \mathrm{Mn}(\mathrm{OH})_{2}$ will precipitate as one of the final productions. Then, Ta residues are washed and dried. Additionally, $48 \mathrm{wt} . \%$ of Ta residues and $52 \mathrm{wt} . \%$ of $\mathrm{FeCl}_{2}$ are mixed evenly and heated at $450{ }^{\circ} \mathrm{C}$ for $3 \mathrm{~h}$ by tube furnace. The gas of $\mathrm{TaCl}_{5}$ will generate and condense into the solid as the final production. In this study, the purity of $\mathrm{Mn}(\mathrm{OH})_{2}$ and $\mathrm{TaCl}_{5}$ is $98.5 \%$ and $99 \%$, respectively; the recovery of $\mathrm{Mn}$ and Ta is $98 \%$ and $94 \%$, respectively.

Author Contributions: Conceptualization, W.-S.C., C.-Y.H. and C.-H.L.; Data curation, C.-Y.H.; Formal analysis, C.-Y.H.; Investigation, C.-Y.H.; Methodology, W.-S.C., C.-Y.H. and C.-H.L.; Supervision, W.-S.C. and C.-H.L.; Validation, C.-Y.H. and C.-H.L.; Visualization, C.-Y.H.; Writing-original draft, C.-Y.H.; and Writing-review and editing, C.-Y.H. and C.-H.L. All authors have read and agreed to the published version of the manuscript.

Funding: This research received no external funding.

Acknowledgments: We wish to acknowledge the support of the Laboratory of Resources Circulation (LRC) at National Cheng Kung University.

Conflicts of Interest: The authors declare no conflict of interest.

\section{References}

1. Balde, V.F.C.P.; Gray, V.; Kuehr, R.; Stegmann, P. The Global E-Waste Monitor 2017; United Nations University, IAS-SCYCLE: Bonn, Germany, 2017.

2. Bleiwas, J.P.D.; Yager, T. Shift in Global Tantalum Mine Production, 2000-2014; U.S. Geological Survey: Reston, VA, USA, 2015.

3. Bloodworth, A. Track flows to manage technology-metal supply. Nature 2014, 505, 19-20. [CrossRef] [PubMed]

4. Ekeberg, A.G.T. Who Discovered Tantalum and When. Available online: https://www.tanb.org/about-tantalum/tantalumhistory (accessed on 15 October 2021).

5. Li, X.; Yu, X.; Wang, C.; Tan, L. Preparation method of porous tantalum. Sci. Tech. Inn. Her. 2008, 1, 83-85.

6. Gonzalez, J.; Gennari, F.; Bohé, A.; Ruiz, M.D.C.; Rivarola, J.; Pasquevich, D. Chlorination of niobium and tantalum ore. Thermochim. Acta 1997, 311, 61-69. [CrossRef]

7. Buchert, A.M.M.; Bleher, D.; Pingel, D. Recycling Critical Raw Materials from Waste Electronic Equipment; Oko-Institut e.V.: Freiburg, Germany, 2012.

8. Buchert, D.S.M.; Bleher, D. Critical Metals for Future Sustainable Technologies and their Recycling Potential; Oko-Institut e.V.: Freiburg, Germany, 2009.

9. Brunette, B. The Basics \& Benefits of Tantalum \& Ceramic Capacitors. Passiv. Compon. Blog. 2019. Available online: https: / / passive-components.eu/the-basics-benefits-of-tantalum\%02ceramic-capacitors (accessed on 17 October 2021).

10. Commission, E. Critical Raw Materials for the EU- Technical Report Report of the Ad-hoc Working Group on Defining Critical Raw Materials. Eur. Comm. 2010, 1-84.

11. Agrawal, M.; Singh, R.; Ranitović, M.; Kamberovic, Z.; Ekberg, C.; Singh, K.K. Global market trends of tantalum and recycling methods from Waste Tantalum Capacitors: A review. Sustain. Mater. Technol. 2021, 29, e00323. [CrossRef]

12. Singh, K.K.; Verma, H.R.; Mankhand, T.R. Comparative study of printed circuit board recycling by cracking of internal layers using organic solventsdimethylformamide and dimethylacetamide. J. Clean. Prod. 2016, 142, 1721-1727.

13. TIC. Bulletin No 172: Announcing the Anders Gustaf Ekeberg Tantalum Prize; Tantalum-Niobium International Study Center: Lasne, Belgium, 2018; Available online: https:/ /www.tanb.org/images/T_I_C_Bulletin_no_172_(January2018).pdf (accessed on 30 November 2021).

14. Mineta, K.; Okabe, T.H. Development of a recycling process for tantalum from capacitor scraps. Phys. Chem. Solids 2005, 66, 318-321. [CrossRef]

15. Niu, B.; Xu, Z.; Chen, Z. Application of pyrolysis to recycling organics from waste tantalum capacitors. J. Hazard. Mater. 2017, 335, 39-46. [CrossRef] [PubMed]

16. Chen, Z.; Niu, B.; Zhang, L.; Xu, Z. Vacuum pyrolysis characteristics and parameter optimization of recycling organic materials from waste tantalum capacitors. J. Hazard. Mater. 2018, 342, 192-200. [CrossRef] [PubMed]

17. Ho, H.-J.; Chen, W.S.; Lin, K.-Y. Hydrometallurgical Process for Tantalum Recovery from Epoxy-Coated Solid Electrolyte Tantalum Capacitors. Materials 2019, 12, 1220. [CrossRef] 
18. Zhou, W.W.Y.; Qiu, K. Recovery of materials from waste printed circuit boards by vacuum pyrolysis and vacuum centrifugal separation. Waste Manag. 2010, 30, 2299-2304. [CrossRef] [PubMed]

19. Sasaki, S.I.M.; Nasu, K.; Quitain, A.T.; Goto, M. Recovery of tantalum from capacitor with solvothermal treatment. ISFR 2011 Toledo 2011, 147-148.

20. Katanoa, S.; Wajima, T.; Nakagome, H. Recovery of Tantalum Sintered Compact from Used Tantalum Condenser Using Steam Gasification with Sodium Hydroxide. ICESD 2014, 10, 182-186. [CrossRef]

21. Niu, B.; Xu, Z.; Chen, Z. Recovery of Tantalum from Waste Tantalum Capacitors by Supercritical Water Treatment. ACS Sustain. Chem. Eng. 2017, 5, 4421-4428. [CrossRef]

22. El-Hussaini, O.; Mahdy, M. Sulfuric acid leaching of Kab Amiri niobium-tantalum bearing minerals, Central Eastern Desert, Egypt. Hydrometallurgy 2002, 64, 219-229. [CrossRef]

23. Wu, B.; Shang, H.; Wen, J.-K. Sulfuric acid leaching of low-grade refractory tantalum-niobium and associated rare earths minerals in Panxi area of China. J. Rar. Met. 2015, 34, 202-206. [CrossRef]

24. Micheau, C.; Lejeune, M.; Arrachart, G.; Draye, M.; Turgis, R.; Michel, S.; Legeai, S.; Pellet-Rostaing, S. Recovery of tantalum from synthetic sulfuric leach solutions by solvent extraction with phosphonate functionalized ionic liquids. Hydrometallurgy 2019, 189, 105107. [CrossRef]

25. Nikolaev, A.I.; Maiorov, V.G. New approaches to niobium and tantalum extraction technology. Dokl. Chem. 2007, 415, 167-169. [CrossRef]

26. Okada, T. Manufacturing of special nibium oxides for optical and ceramic applications. In Proceedings of the International Symposium Niobium, Orlando, FL, USA, 2-5 December 2001; pp. 141-8094.

27. Zhu, Z.; Cheng, C.Y. Solvent extraction technology for the separation and purification of niobium and tantalum: A review. Hydrometallurgy 2011, 107, 1-12. [CrossRef]

28. Nahraa, M.; Svecova, L.; Chaînet, E. Pentavalent tantalum reduction mechanism from 1-butyl-3-methyl pyrrolidinium bis(trifluoromethylsulfonyl)imide ionic liquid. Electrochim. Acta 2015, 182, 891-899. [CrossRef]

29. Turgis, R.; Arrachart, G.; Michel, S.; Legeai, S.; Lejeune, M.; Draye, M.; Pellet-Rostaing, S. Ketone functionalized task specific ionic liquids for selective tantalum extraction. Sep. Purif. Technol. 2018, 196, 174-182. [CrossRef]

30. Niu, B.; Chen, Z.; Xu, Z. An integrated and environmental-friendly technology for recovering valuable materials from waste tantalum capacitors. J. Clean. Prod. 2017, 166, 512-518. [CrossRef]

31. Niu, B.; Chen, Z.; Xu, Z. Recycling waste tantalum capacitors to synthesize high value-added $\mathrm{Ta}_{2} \mathrm{O}_{5}$ and polyaniline-decorated $\mathrm{Ta}_{2} \mathrm{O}_{5}$ photocatalyst by an integrated chlorination-sintering-chemisorption process. J. Clean. Prod. 2020, 252, 117206. [CrossRef]

32. Niu, B.; Chen, Z.; Xu, Z. Method for Recycling Tantalum from Waste Tantalum Capacitors by Chloride Metallurgy. ACS Sustain. Chem. Eng. 2017, 5, 1376-1381. [CrossRef]

33. de Michelis, I.; Ferella, F.; Karakaya, E.; Beolchini, F.; Vegliò, F. Recovery of zinc and manganese from alkaline and zinc-carbon spent batteries. J. Power Sources 2007, 172, 975-983. [CrossRef]

34. Furlani, G.; Moscardini, E.; Pagnanelli, F.; Ferella, F.; Vegliò, F.; Toro, L. Recovery of manganese from zinc alkaline batteries by reductive acid leaching using carbohydrates as reductant. Hydrometallurgy 2009, 99, 115-118. [CrossRef]

35. Francesco, F.; Michelis, I.D.; Beolchini, F.; Innocenzi, V.; Vegli, F. Extraction of Zinc and Manganese from Alkaline and Zinc-Carbon Spent Batteries by Citric-Sulphuric Acid Solution. Int. J. Chem. Eng. 2010, 2010, 13. [CrossRef]

36. Sayilgan, E.; Yigit, N.O.K.; Civelekoglu, G.; Kitis, M. Acidic leaching and precipitation of zinc and manganese from spent battery powders using various reductants. J. Hazard Mater. 2010, 173, 137-143. [CrossRef] [PubMed]

37. Buzatu, M.; Săceanu, S.; Petrescu, M.; Ghica, G.; Buzatu, T. Recovery of zinc and manganese from spent batteries by reductive leaching in acidic media. J. Power Sources 2014, 247, 612-617. [CrossRef]

38. Chen, W.-S.; Liao, C.-T.; Lin, K.-Y. Recovery Zinc and Manganese from Spent Battery Powder by Hydrometallurgical Route. Energy Procedia 2016, 107, 167-174. [CrossRef] 